\title{
Visual challenges using Visual Display Units (VDU) in office landscapes
}

\author{
Magne Helland, Gunnar Horgen \\ Department of Optometry and visual science, Buskerud University College \\ P.O. Box 235, N-3601 Kongsberg, Norway
}

\begin{abstract}
A total of 85 VDU operators, in three main Scandinavian Alcatel-Lucent headquarters, were followed in a process moving from single occupancy offices to office landscapes. This paper discusses the visual challenges and implications in such a change in location. By careful design and construction of an office landscape with regards to lighting and visual conditions transfer from a small office to an office landscape may be acceptable from a visual-ergonomic point of view. In the oral presentation recommendation on how to avoid visual problems will be discussed.
\end{abstract}

Keywords: VDU workplaces, visual ergonomics, lighting conditions, visual discomfort, office landscape

\section{Introduction}

In Norway and in many European countries there has been a tendency for many companies to move their office locations from buildings with small or single cell offices to office landscapes. This applies in particular for companies with a work force where many employees spend many daily working hours using Visual Display Units (VDU).

It is well known that visually demanding VDU work can be associated with a high prevalence of visual discomfort $[1,2]$ and to optimize the working conditions both work station ergonomics, the office environment, and lighting must be considered [3, 4, 5]. For most European countries national versions of EU Directive 90/270 EEC on the minimum safety and health requirements for work with VDUs have been implemented. This imply that all workers that spend a significant part of their work day in front of a VDU, has the right, by law, to have an optimized work place regarding both ergonomic and lighting conditions, and also to have an eye examination if there are indications that this is needed. If the eye examination reveals a need for specially designed spectacles for the VDU work, he/she should get these paid by the employer. [6]

\section{Methods}

Three prospective field studies were performed following the VDU workers in the three main Scandinavian offices to a telecom company (Alcatel-Lucent) when moving from a location with mainly single cell offices to an office landscape. This was done for 34 workers in Oslo [7], 32 workers in Stockholm [8] and 19 workers in Copenhagen [9].

In addition to an ergonomically optimized work station design both visual conditions and lighting were taken into consideration. The workers subjective judgment of their visual situation and surroundings was assessed by a questionnaire based upon Visual
Analogue Scales (VAS), both before and after, moving into the office landscape. Optometric evaluation of the workplaces was done, and the participants were offered an eye examination and new glasses specially designed for VDU-work were supplied when needed.

\section{Results and Discussion}

The main scientific results from the studies are presented in the papers from the three respective Scandinavian locations $[7,8,9]$. The practical implications and recommendations will be presented and discussed in the oral presentation at IEA 2012.

One important conclusion from the work is that by careful design and construction of an office landscape with regard to lighting and visual conditions, transfer from small offices may be acceptable from a visual-ergonomic point of view. However, if the lighting and visual conditions in the operators' previous singleoccupancy office had been optimized according to current recommendations, as was the situation for the VDU workers in Oslo, a transfer to an office landscape is very challenging. Despite the fact that the lighting system in the new office landscape was optimized regarding both light level and glare, the subjective assessment showed that the operators reported significantly worse lighting conditions in the office landscape compared to their previous single occupancy offices, $11.8(1.9-21.7)$ VAS as group mean difference with $95 \%$ confidence interval $(p=0.021)$ (Figure 1) [7].

The glare condition was also reported to be less satisfactory (not significant), 12.3 (-0.3 to 24.9) VAS as group mean difference with $95 \%$ confidence interval $(p=0.056)$.

Also the subjective assessment of visual discomfort showed a significant increase in the office landscape for the VDU workers in the Oslo study (Figure 2) [7]. 


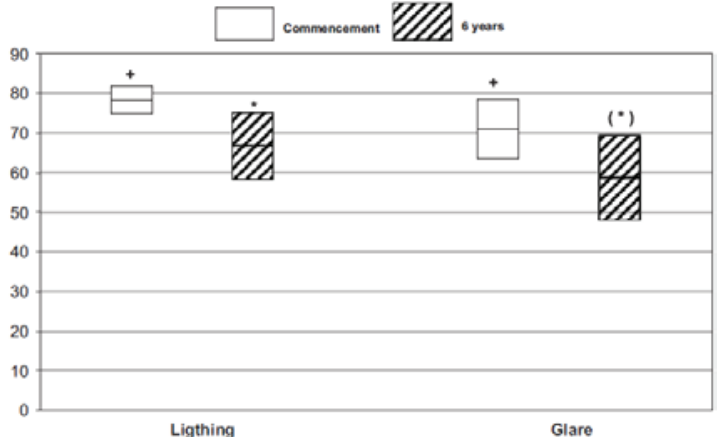

Fig. 1 Subjective assessment of the lightning and glare conditions. Mean with $95 \%$ confidence interval at commencement and 6 years $(100 \mathrm{~mm}$ VAS $0=$ extreme problems, $100=$ no problems). An asterisk $(*)$ indicates a significant difference when comparing with the column containing a (+). An asterisk in brackets $((*))$ is very close to a significant difference.

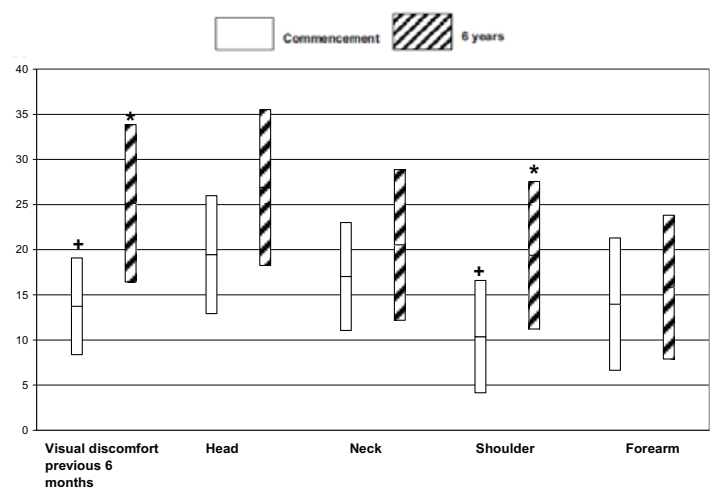

Fig. 2 Subjective assessment of visual discomfort and pain in different body parts ( $\mathrm{n}=34 \mathrm{VDU}$ operators). Mean with $95 \%$ confidence interval at commencement and 6 years $(100 \mathrm{~mm}$ VAS, $0=$ extreme problems, $100=$ no problems). An asterisk $(*)$ indicates a significant difference when comparing with the column containing a $(+)$.

Here an increase in VAS on 10.7 (1.9 to 19.5$)$ as group mean difference with $95 \%$ confidence interval $(p=0.019)$. Comparison of different types of eye symptoms showed that stinging and itching of the eyes increased significantly in the office landscape $(p=0.027)$. This was also true for blurred vision $(p=0.011)$. However, no significant differences were reported for feeling of tired eyes, redness of the eyes, gritty sensation of the eyes, or sensitivity to light. Glare showed a weak but significant correlation with visual discomfort, $r s=0.35(\mathrm{p}=0.040)$.

In general, moving into an office landscape might be problematic due to high luminance from the windows giving glare and increased contrast reduction in the work area. It is also more problematic for each individual worker to adjust venetian blinds and additional work station illumination (if present) without causing a more problematic situation for the other workers.

By careful design and construction of an office landscape with regard to lighting and visual conditions, transfer from small offices may be acceptable from a visual-ergonomic point of view.

Concerning visual corrections and the national Scandinavian implementation documents of the EU directive for computer work (90/270/EEC) a recent Finish study showed that while a total of $59 \%$ of employers reported that cost of VDU glasses was refunded, whereas the figure for employees was only $37 \%$ [10]. The same study concludes that employees' sight examinations and compensations for eyeglasses should be promoted in computer work.
Some of the main implications from the three Scandinavian studies $[7,8,9]$ can be summarized in these general recommendations for VDU workstations in office landscapes:

- General guidelines and recommendations for VDUwork should be followed

LCD screens are preferable due to a less contrast reduction compared with CRT screens

The general office lighting should be carefully designed regarding illumination, luminance and contrast reduction

Venetian blinds should be installed and used to reduce glare from the windows

VDU work places should not be placed too close to the windows

A gaze direction parallel to the window walls are preferable

VDU operators should be offered optometric care and special corrections if indicated.

Optometric care of VDU operators is of special importance for presbyopic persons (age above 40-45 years).

\section{References}

[1] M. Rosenfield, Computer vision syndrome: a review of ocular causes and potential treatments. Ophthalmic Physiol Opt, 2011, 31, 502-515.

[2] D. Thomson, The computerized office. Part one - a site for sore eyes. Optician, 1998, 215 (5651), 18-24.

[3] J.E. Sheedy, P.G. Shaw-McMinn, Diagnosing and Treating Computer-Related Vision Problems. Butterworth-Heinemann, 2003 (ISBN 0-7506-7404-0).

[4] Human Factors and Ergonomics Society. ANSI/HFES 1002007 Human Factors Engineering of Computer Workstations. 2007.

[5] P. Wolkoff, J.K. Nøjgaard, C. Frank, P. Skov, Review article - The modern office environment desiccates the eyes? Indoor Air, 2006, 16, 258-265.

[6] EU 90/270/EEC, Council Directive of 29 May 1990 on the minimum safety and health requirements for work with display screen equipment (fifth individual Directive within the meaning of Article 16 (1) of Directive 87/391/EEC) (90/270/EEC)

[7] M. Helland, G. Horgen, T.M. Kvikstad, T. Garthus, J.R. Bruenech, A. Aarås, Musculoskeletal, visual and psychosocial stress in VDU operators after moving to an ergonomically designed office landscape. Applied Ergonomics, 2008, 39 (3), 284-295.

[8] M. Helland, G. Horgen, T.M. Kvikstad, T. Garthus, A. Aarås, Will musculoskeletal, visual and psychosocial stress change for visual display unit (VDU) operators when moving from a single person office to an office landscape? International Journal of Occupational Safety and Ergonomics (JOSE) 2008 , 14 (3), 259-274

[9] M. Helland, G. Horgen, T.M. Kvikstad, T. Garthus, A. Aarås, Will musculoskeletal and visual stress change when Visual Display Unit (VDU) operators move from small offices to an ergonomically optimized office landscape? Applied Ergonomics 2011, 42 (6), 839-845.

[10] T. Niskanen, J. Lehtelä, R. Ketola, E. Nykyri, Results of Finnish national survey on EU legislation concerning computer work. Applied Ergonomics 2010, 41 (4), 542-548. 